Historic, archived document

Do not assume content reflects current scientific knowledge, policies, or practices. 

Forest Service

Northeastern

Research Station

Research Note NE-376

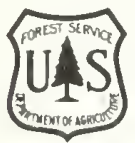

\author{
Michael A. Menzel \\ Jennifer M. Menzel \\ Steven B. Castleberry \\ James Ozier \\ W. Mark Ford \\ John W. Edwards
}
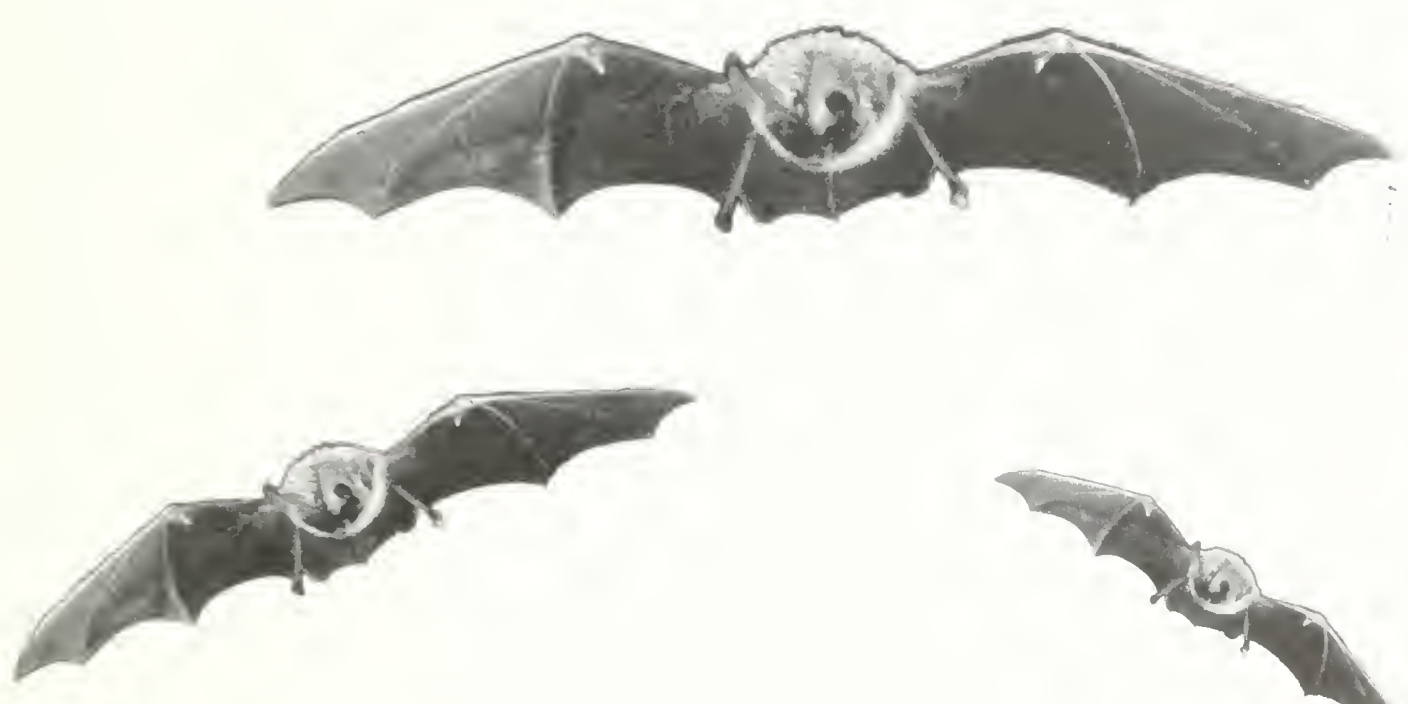

\title{
Illustrated Key to Skins and Skulls of Bats in the Southeastern and Mid-Atlantic States
}

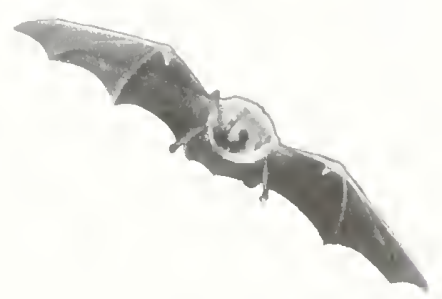

\footnotetext{
Abstract

In teaching students and technicians how to identify the skins and skulls of southeastern bats in the field and laboratory, it was necessary to develop an illustrated key that makes identification both easy and reliable. Many of the existing keys are poorly illustrated, include bat species that are not applicable, and/or contain univariate discriminatory measurements that can result in inaccurate identifications. We constructed a key that allows users to easily and accurately identify the skin and skulls of 17 bat species that inhabit the Southeastern and Mid-Atlantic regions (north of central Florida and east of the Mississippi River).
}

MICHAEL A. MENZEL is a wildlife biologist with West Virginia University's Division of Forestry; JENNIFER M. MENZEL is a research wildlife biologist with the USDA Forest Service's Northeastern Research Station; STEVEN B. CASTLEBERRY is a wildlife biologist and assistant professor with the University of Georgia’s D. B. Warnell School of Forest Resources; JAMES OZIER is a wildlife biologist with the Georgia Department of Natural Resources; W. MARK FORD is a research wildlife biologist with the Northeastern Research Station; JOHN W. EDWARDS is a wildlife biologist and assistant professor with West Virginia University's Division of Forestry. 
Table 1.-Dental formulas for the bats in the Southeastern and Mid-Atlantic regions ( $\mathrm{I}=$ Incisors, $\mathrm{C}=$ Canines, $\mathrm{Pm}=$ Premolars, $\mathrm{M}=$ Molars $)$

\begin{tabular}{|c|c|c|c|c|c|c|c|c|c|}
\hline \multirow[b]{2}{*}{ Species } & \multicolumn{4}{|c|}{ Upper teeth $^{z}$} & \multicolumn{4}{|c|}{ Lower teeth ${ }^{\mathrm{a}}$} & \multirow[t]{2}{*}{ Total $(\mathrm{x} 2)$} \\
\hline & $\mathrm{I}$ & $\mathrm{C}$ & $\mathrm{Pm}$ & $\bar{M}$ & $\bar{I}$ & $\mathrm{C}$ & $\mathrm{Pm}$ & $\bar{M}$ & \\
\hline Pipistrellus subflavus & 2 & 1 & 2 & 3 & 3 & 1 & 2 & 3 & 34 \\
\hline Nycticeius humeralis & 1 & 1 & 1 & 3 & 3 & 1 & 2 & 3 & 30 \\
\hline Myotis leibii & 2 & 1 & 3 & 3 & 3 & 1 & 3 & 3 & 38 \\
\hline M. austroriparius & 2 & 1 & 3 & 3 & 3 & 1 & 3 & 3 & 38 \\
\hline M. septentrionalis & 2 & 1 & 3 & 3 & 3 & 1 & 3 & 3 & 38 \\
\hline$M$. lucifugus & 2 & 1 & 3 & 3 & 3 & 1 & 3 & 3 & 38 \\
\hline M. sodalis & 2 & 1 & 3 & 3 & 3 & 1 & 3 & 3 & 38 \\
\hline M. grisescens & 2 & 1 & 3 & 3 & 3 & 1 & 3 & 3 & 38 \\
\hline Lasionycteris noctivagans & 2 & 1 & 2 & 3 & 3 & 1 & 3 & 3 & 36 \\
\hline Corynorhinus rafinesquii & 2 & 1 & 2 & 3 & 3 & 1 & 3 & 3 & 36 \\
\hline Corynorhinus townsendii & 2 & 1 & 2 & 3 & 3 & 1 & 3 & 3 & 36 \\
\hline Lasiurus borealis & 1 & 1 & 2 & 3 & 3 & 1 & 2 & 3 & 32 \\
\hline L. seminolus & 1 & 1 & 2 & 3 & 3 & 1 & 2 & 3 & 32 \\
\hline L. intermedius & 1 & 1 & 1 & 3 & 3 & 1 & 2 & 3 & 30 \\
\hline L. cinereus & 1 & 1 & 2 & 3 & 3 & 1 & 2 & 3 & 32 \\
\hline Eptesicus fuscus & 2 & 1 & 1 & 3 & 3 & 1 & 2 & 3 & 32 \\
\hline Tadarida brasiliensis & 1 & 1 & 2 & 3 & $2 / 3$ & 1 & 2 & 3 & $30 / 32$ \\
\hline
\end{tabular}

${ }^{a}$ Number of teeth in each side of jaw.

There has been renewed research emphasis on the distribution and natural history of bats in the Southeastern United States (Menzel et al. 2000). For example, one-half of the 14 peer-reviewed manuscripts and 4 technical reports on the natural history of bats in Georgia have been published within the past 5 years. Yet numerous questions posed by land managers and ecologists remain unanswered. One impediment to expanding research on and monitoring of southeastern bats was the lack of a reliable key for identifying bats in the field. Many existing keys contain information about bat species that are found in the Southeast (Jenkins 1949; Golley 1962; Barbour and Davis 1969; Hoffmeister 1989; Sealander and Heidt 1990; Schmidley 1991; Whitaker and Hamilton 1998), but most are difficult to use or are unreliable because they are poorly illustrated, require examination of the lower jaw, or contain univariate discriminatory measurements.

One of the first illustrated keys to the skins and skulls of southeastern bats was published in The Mammals of Georgia: A Study of Their Distribution and Functional Role in the Ecosystem (Golley 1962). Although of some utility, this key contains morphological measurements that conflict with measurements in other keys. For example, The Mammals of Georgia describes the southeastern myotis (Myotis austroriparius) as having an interorbital breadth of less than $4 \mathrm{~mm}$, while The Bats of Texas (Schmidly 1991) describes the interorbital breadth of southeastern myotis as being more than $4 \mathrm{~mm}$. A recent quantitative comparison of 19 skull measurements among six myotid species found in the Southeast revealed that skulls of southeastern myotids could not be identified reliably based on any univariate measurement. ${ }^{1}$

Additionally, our prior experience in teaching students and field technicians to identify the bats in the Southeastern and Mid-Atlantic regions using existing keys suggested that additional illustration of diagnostic characteristics, such as those of the keeled calcar of the Indiana bat (Myotis sodalis), would be helpful in identifying some species. Thus, the need for a wellillustrated, accurate, and simple key to the skins and skulls of the bats of the Southeast prompted us to develop the illustrated key presented here.

\section{Developing the Key}

In constructing the key, we used measurements from museum specimens, information from publications about

${ }^{1}$ Menzel, M.A.; Boone, J. L.; Menzel, J. M.; Hauge, M. Mensural discrimination among six southeastern myotids. In preparation. 


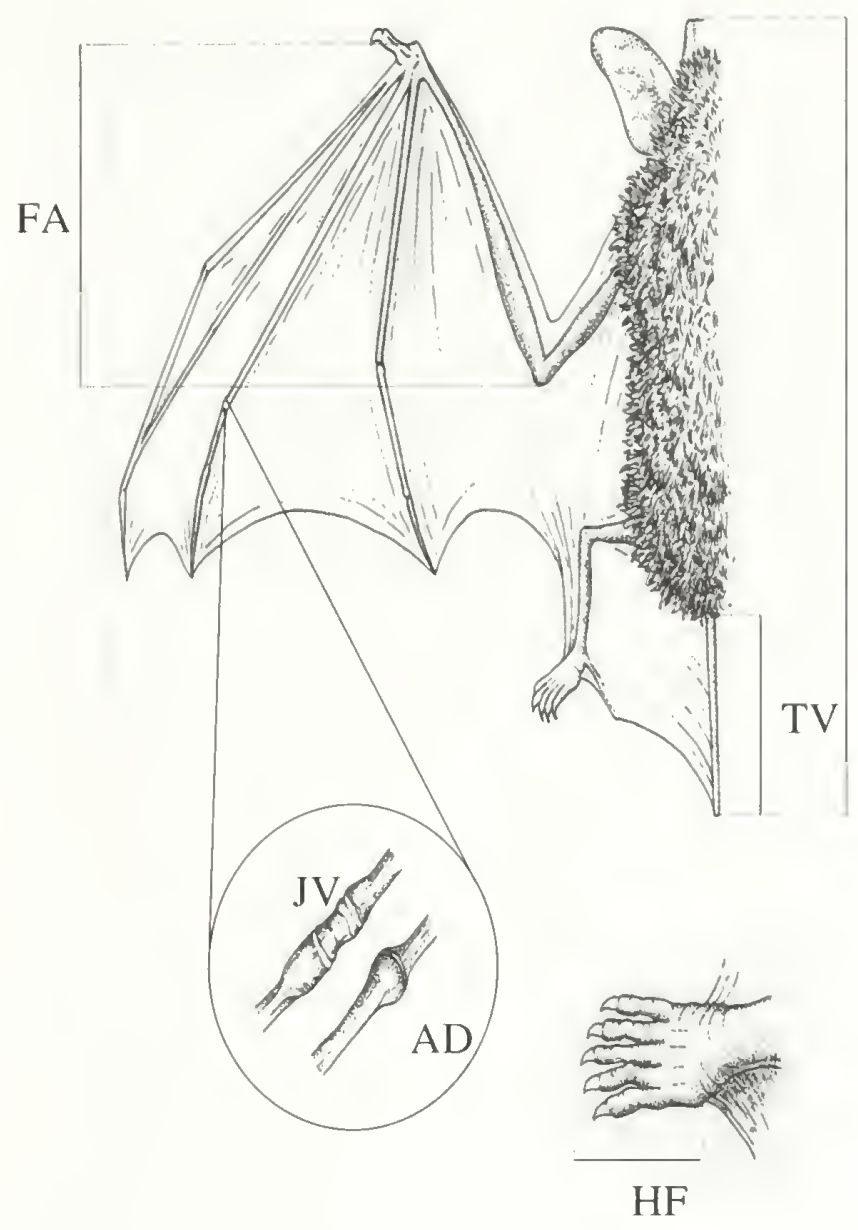

bat morphological characteristics, and data from existing dichotomous keys (Jenkins 1949; Golley 1962; Barbour and Davis 1969; Hoffmeister 1989; Schmidley 1991). All measurements taken exclusively for our key were from specimens from the Georgia Museum of Natural History at the University of Georgia. Because the lower jaw often is damaged or missing from museum skeletal specimens or skulls found in the field, we constructed our key so that the lower jaw is not required for identification.

Many existing keys to southeastern bats do not discriminate between the skulls of eastern red bats (Lasiurus borealis) and Seminole bats (L. seminolus). We incorporated distinguishing data on the size of the protuberance of the lacrimal ridge (shelf), that proved to be nearly 75-percent accurate (Lowery 1974; Laerm et al. 1999). Not included in The Mammals of Georgia (Golley 1962), we also included discriminatory information on the eastern small-footed myotis (Myotis leibii) in our key to the skins. We did not provide information about the differentiation of the myotids for the skull key. With the dichotomous key to the skulls presented here, the user can classify a skull only as belonging to the genus Myotis. Although the skins of the six Myotis species that are found in the Southeastern and Mid-Atlantic regions can be
TL

Figure 1.-Standard bat measurements include total length (TL), tail length (TV), forearm length (FA), and foot length (HF). The inset illustrates the extent of fusion in the epiphyseal gap of the finger joints of adults and juveniles. Adult joints (AD) appear fused and consist of a single protuberance; juvenile joints (JV) are not fused (cartilaginous plates remain in the joints) and consist of two protuberances or a single protuberance that is larger and more tapered than in adult joints.

identified accurately using qualitative characteristics or univariate metrics, myotid skulls cannot be distinguished reliably using qualitative characteristics, univariate metrics, or bivariate scattergrams. ${ }^{1}$ Skulls of the six southeastern myotid species can be identified accurately (96+ percent correct classification) using complex multivariate techniques such as discriminate function analysis.

Exclusive of myotids, many bat skulls can be identified by counting the number of teeth in one upper quadrant (one-half of the upper jaw) and measuring the greatest length of the skull (from the posterior-most margin to the anterior-most portion, not including the incisors) and comparing these measures to dental formulae of each species (Table 1) and the skull key.

Locations of six standard body measurements used in identification - total length (TL), tail length (TV), foot length (HF), ear length (E), forearm length (FA), and tragus length (TR) - are illustrated in Figures 1 and 2. These measurements can be taken on dead specimens prior to preparation or on live specimens prior to release. Our key was designed using characteristics and measurements recorded from adult individuals and may 


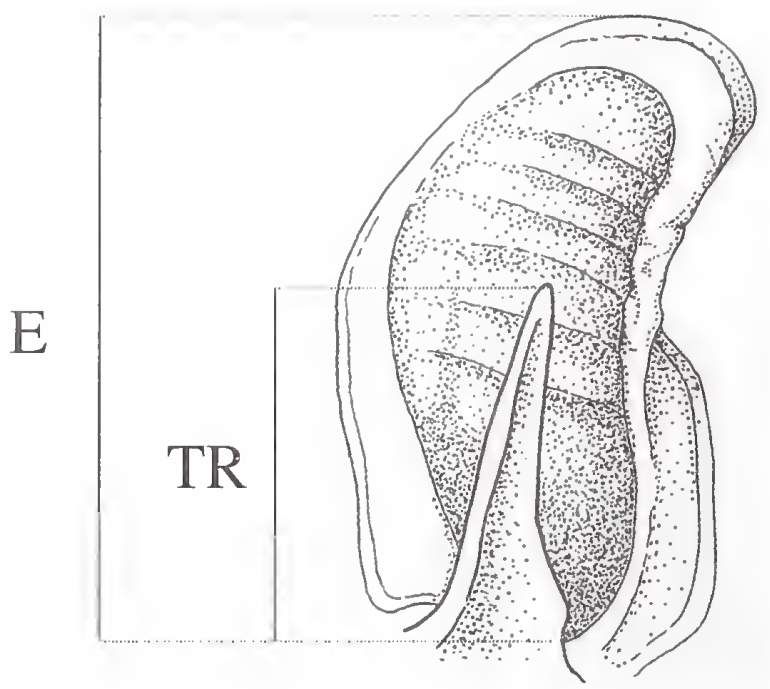

Figure 2.-Ear (E) and tragus length (TR) measurements.

not be reliable for identifying juveniles. Bats can be placed reliably in juvenile or adult age classes by examining the extent of epiphyseal-diaphyseal fusion in the finger joints (Anthony 1988). Cartilaginous plates are not apparent in the finger joints of adults, which consists of a single, knobby protuberance (Fig. 1). Cartilaginous plates are apparent in juvenile finger joints, which consist of two protuberances with a slight taper between, or a single protuberance that is much longer and more tapered at both ends than that in adult joints (Fig. 1). The most effective way to observe the cartilaginous plates is by backlighting the wing and looking for semitransparent sections in the joints of the phalanges.

\section{Key to Bat Skins}

1. a. One-third or more of the tail extends beyond uropatagium (Fig. 3a)-Brazilian free-tailed bat (Tadarida brasiliensis)

b. Tail does not extend beyond uropatagium or only slightly (Fig. 3b) - 2

2. a. At least one-third of the dorsal surface of uropatagium furred-3

b. Dorsal surface of uropatagium not furred or slightly furred at the junction with the body -7

3. a. Pelage black; tips of hairs frosted with white- -4

b. Pelage dark red, mahogany, or yellow-5
A

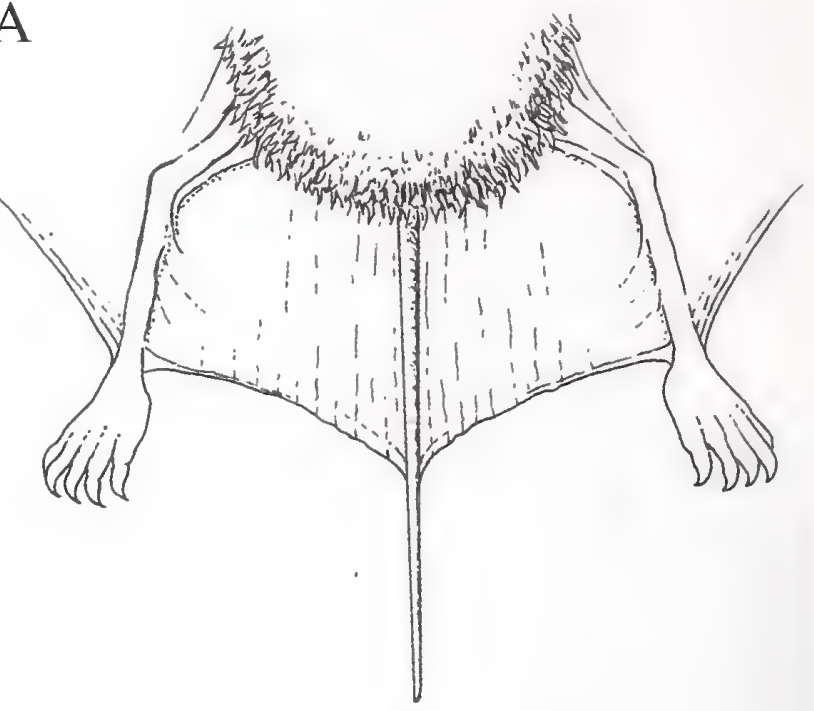

B

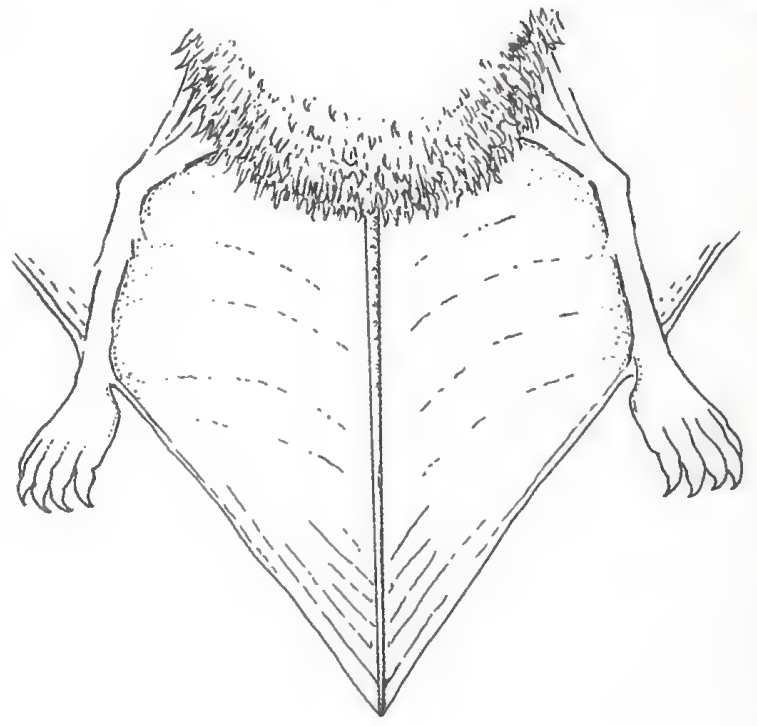

Figure 3.-Contrast between the tail and uropatagium of the Brazilian free-tailed bat (Tadarida brasiliensis) and the other 15 species of bats that are found in the Southeastern and Mid-Atlantic regions. The tail of the former extends beyond the posterior margin of the uropatagium (A); the tails of the other 15 bat species are enclosed in the uropatagium (B).

4. a. Total length more than $120 \mathrm{~mm}$; uropatagium heavily furred throughout; ear white or yellow with black rim-hoary bat (Lasiurus cinereus)

b. Total length less than $115 \mathrm{~mm}$; posterior one-third of uropatagium bare; ear solid black-silver-haired bat (Lasionycteris noctivagans)

5. a. White shoulder patch absent, yellow coloration, frosting absent-northern yellow bat (Lasiurus intermedius) 


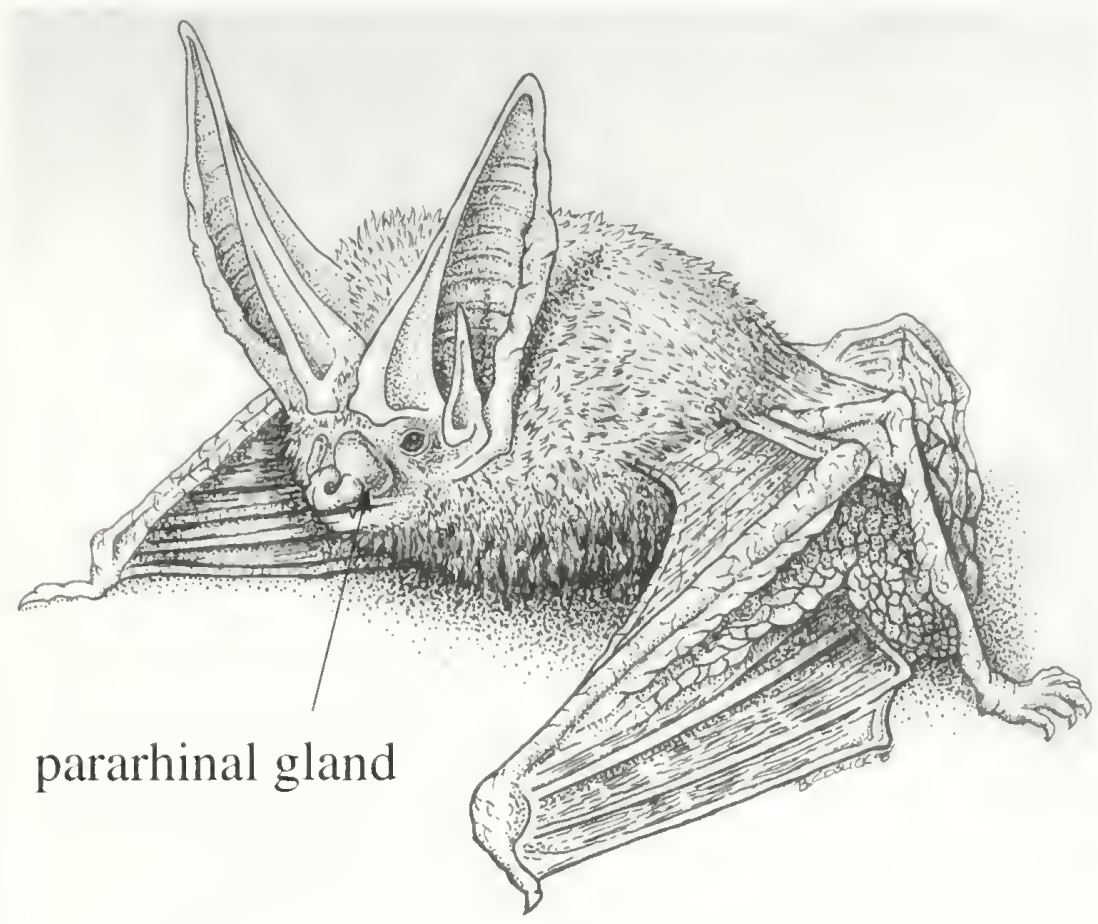

Figure 4.-Location of the pararhinal glands on Rafinesque's big-eared bat (Corynorhinus rafinesquii).
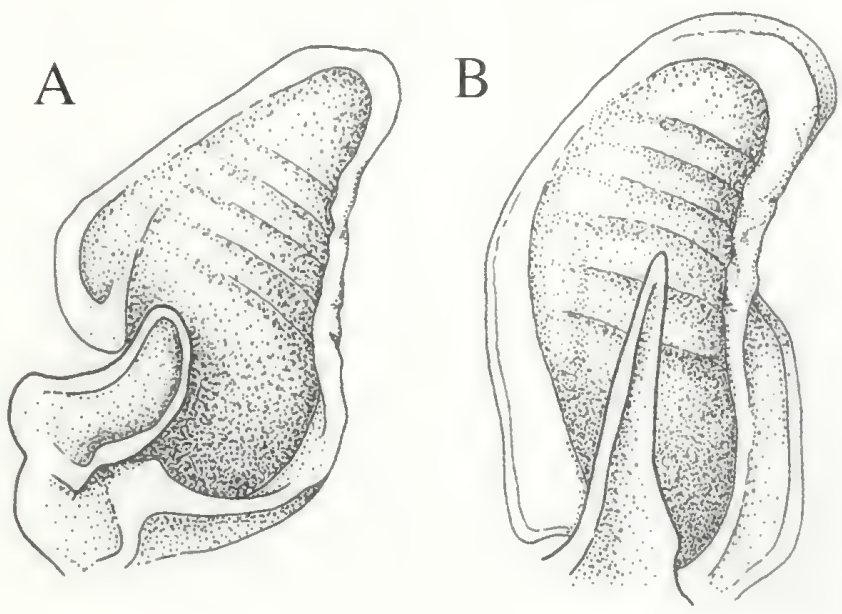

Figure 5.-The eastern pipistrelle (Pipistrellus subflavus) and the evening bat (Nycticius humeralis) have a short, blunt tragus (A); the myotids have a long, pointed, sharp tragus (B).

b. White shoulder patch present, red or mahogany coloration, frosting usually present (except male Lasiurus borealis) - 6

6. a. Pelage bright, brick-red; tips of hair frosted white (except males); face is light red/yellow-eastern red bat (Lasiurus borealis)

b. Pelage dark mahogany; tips of hair frosted white; face is mahogany/red-Seminole bat (Lasiurus seminolus)
7. a. Ears more than $25 \mathrm{~mm}$ long; distinctive pararhinal glands (large bumps, Fig. 4) on either side of nose-8

b. Ears less than $25 \mathrm{~mm}$ long; pararhinal glands not distinct-9

8. a. Toe hair extending past claws; pelage gray to light gray or white from tip to base-Rafinesque's big-eared bat (Corynorhinus rafinesquii)

b. Toe hair not extending past claws; pelage pale brown to black with dark base and tips somewhat buff-Townsend's big-eared bat (Corynorhinus townsendii)

9. a. Total length more than $100 \mathrm{~mm}$, forearm more than $40 \mathrm{~mm}$-big brown bat (Eptesicus fuscus)

b. Total length less than $100 \mathrm{~mm}$, forearm less than 40 $m m-10$

10.a. Tragus (projection within the ear) short, blunt, and curved (Fig. 5a) -11

b. Tragus long, pointed at tip, and straight (Fig. 5b)12

11. a. Dorsal fur tricolored when parted; coloration black at base, yellowish-brown in the middle and dark brown at tips; forearm pink and less than $32 \mathrm{~mm}$ eastern pipistrelle (Pipistrellus subflavus) 
A

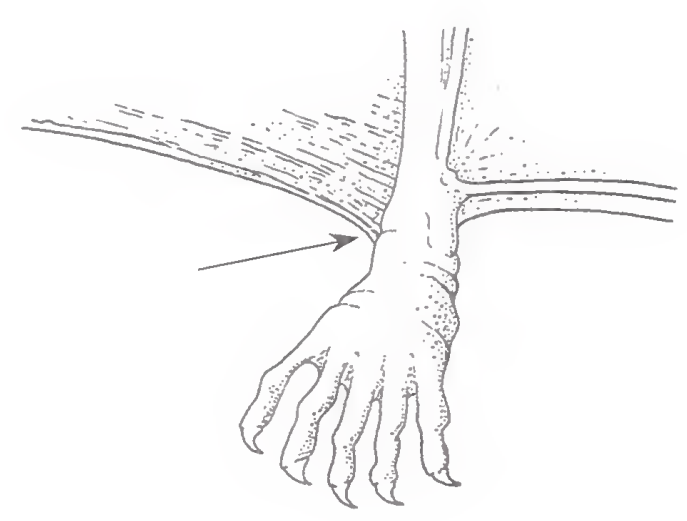

B

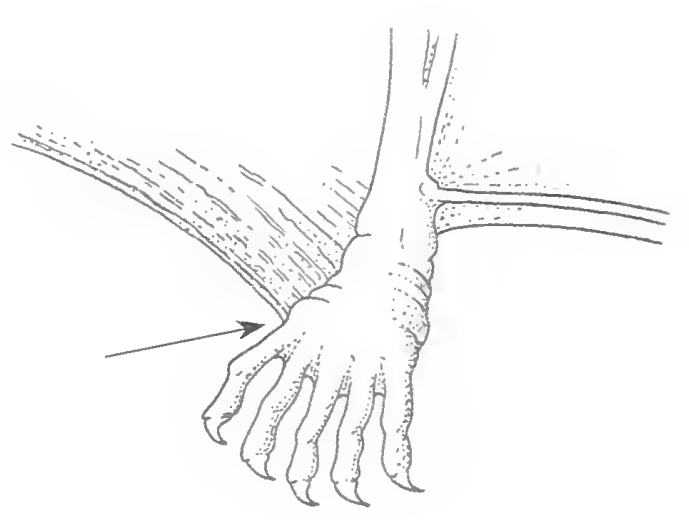

Figure 6.- In the gray bat (Myotis grisescens), the plagiopatagium attaches to the tarsus (A). In the other 5 species of myotids that are found in the Southeastern and Mid-Atlantic regions, the plagiopatagium attaches to the side of the foot (posterior margin of the metatarsals) at the base of the toes $(B)$.

b. Dorsal fur dark brown; forearm dark and more than $32 \mathrm{~mm}$ - evening bat (Nycticeius humeralis)

12.a. Plagiopatagium (wing membrane outside of hind legs) proximal attachment to tarsus (ankle), well below the base of the toes; pelage uniformly gray; hairs not bicolored (Fig. 6a) — gray bat (Myotis grisescens)

b. Plagiopatagium attached to side of foot at the base of toes; pelage not gray; hairs bicolored (Fig. 6b) -13

13. a. Ear more than $16 \mathrm{~mm}$ long; extends more than 2 $\mathrm{mm}$ beyond the tip of nose when laid forwardnorthern long-eared myotis (Myotis septentrionalis)

b. Ear does not extend beyond the tip of nose when laid forward-14
A

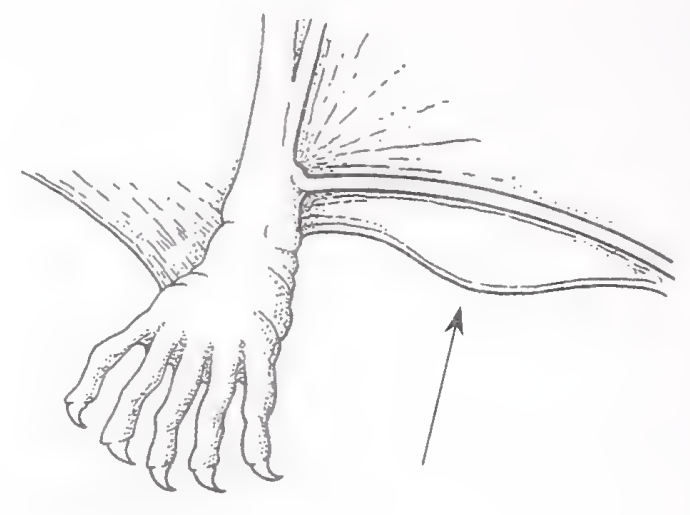

B

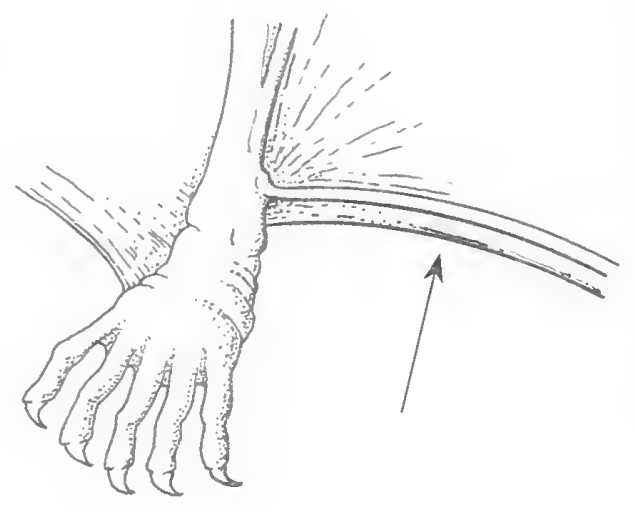

Figure 7.-A keeled calcar (A) is characteristic of Indiana bats (Myotis sodalis) and small-footed myotis (M. leibii); an unkeeled calcar (B) is characteristic of little brown ( $M$. lucifugus) and southeastern $(M$. austroriparius) myotis.

14.a. Calcar keeled (Fig. 7a)-15

b. Calcar not keeled (Fig. 7b) -16

15. a. Foot usually more than $7 \mathrm{~mm}$, forearm usually more than $35 \mathrm{~mm}$; pelage short and wooly; black mask around eyes absent-Indiana bat (Myotis sodalis)

b. Foot usually less than $7 \mathrm{~mm}$, forearm usually less than $35 \mathrm{~mm}$; pelage long and glossy; hairs around eyes black giving the appearance of a black mask-smallfooted myotis (Myotis leibii)

16.a. Tips of hairs are reddish; hair long and glossylittle brown bat (Myotis lucifugus)

b. Tips of hairs are not reddish; hair short and wooly-southeastern myotis (Myotis austroriparius) 


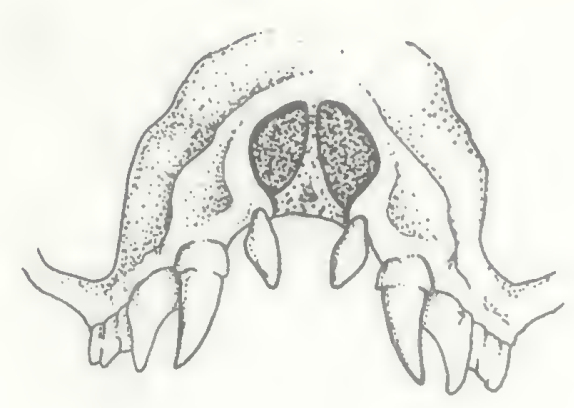

B

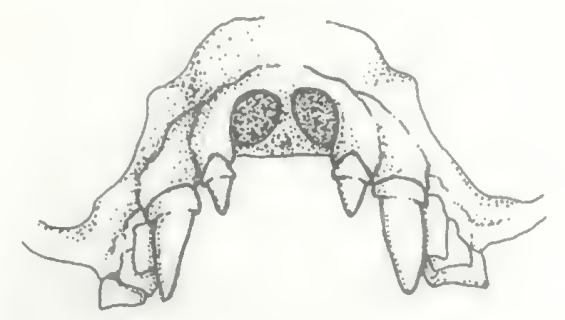

Key to Bat Skulls

1. a. Upper incisors obviously converge at tips (i.e., much closer together at tips than at base, Fig. 8a) Brazilian free-tailed bat (Tadarida brasiliensis)

b. Upper incisors wider at tip than base, equidistant at tip and base, or tips slightly converging (Fig. 8b) -2

2. a. There are nine teeth in upper quadrant (one side of upper jaw)-Myotis spp.

b. Fewer than nine teeth in upper quadrant-3

3. a. Eight teeth in upper quadrant-4

b. Fewer than eight teeth in upper quadrant -7

4. a. Upper incisor bifid (two-cusped)—Rafinesque's big-eared bat (Corynorhinus rafinesquii)

b. Upper incisor unicuspid-5

5. a. Greatest length of skull more than $13.5 \mathrm{~mm}$; rostrum flat with two concavities on dorsal surfacesilver-haired bat (Lasionycteris noctivagans)
Figure 8.-Unlike the upper incisors of other southeastern bats (B), the upper incisors of the Brazilian free-tailed bat (Tadarida brasiliensis) converge at the tips (A).

b. Rostrum sloped with no concavities on dorsal surface -6

6. a. Rostrum strongly sloped; greatest length of skull more than 13 mm-Townsend's big-eared bat (Corynorhinus townsendii)

b. Rostrum gently sloped; greatest length of skull less than $13.5 \mathrm{~mm}$-eastern pipistrelle (Pipistrellus subflavus)

7. a. Seven teeth in upper quadrant -8

b. Six teeth in upper quadrant-11

8. a. Two upper incisors (one large, one minute) - big brown bat (Eptesicus fuscus)

b. One upper incisor-9

9. a. Greatest skull length more than $15.5 \mathrm{~mm}$-hoary bat (Lasiurus cinereus)

b. Greatest skull length less than $15.5 \mathrm{~mm}-10$ 

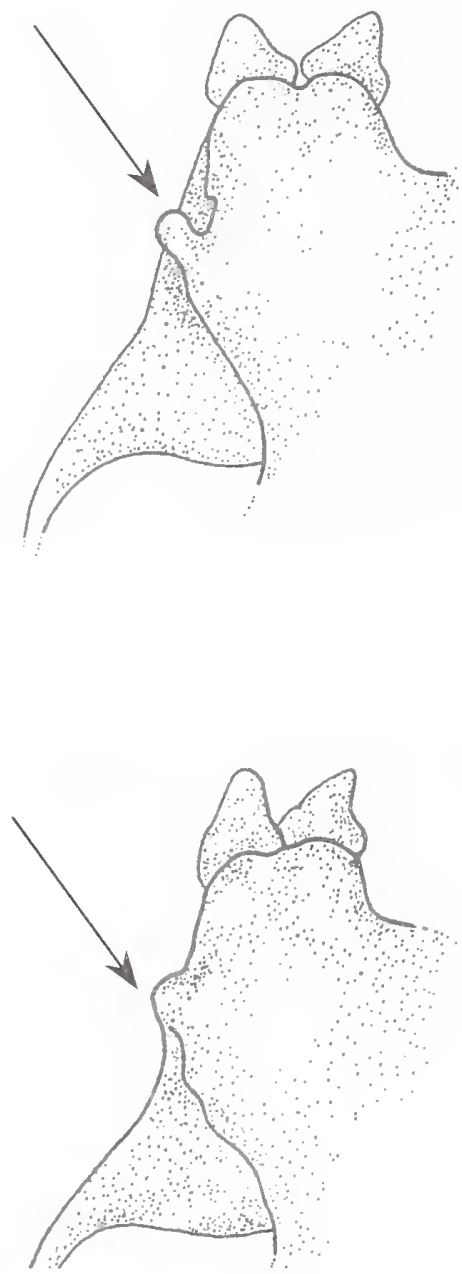

Figure 9.- The lacrimal ridge protuberance of the eastern red bat (Lasiurus borealis) (A) and the Seminole bat (L. seminolus) (B). The dorsal surface view of the upper left skull quadrant is depicted. Note that the two triangular structures at the top are the upper incisor and the upper canine. The hooked structure at the lower left section is the anterior-most section of the zygomatic arch. The lacrimal ridge protuberance (lacrimal shelf) typically is larger in $L$. borealis than in $L$. seminolus.

10. a. Protuberance of the lacrimal ridge (shelf) well developed (Fig. 9a) —eastern red bat (Lasiurus borealis)

b. Protuberance of the lacrimal ridge poorly developed or absent (Fig. 9b) - Seminole bat (Lasiurus seminolus)

11. a. Sagittal crest well developed; greatest length of skull more than $16 \mathrm{~mm}$-northern yellow bat (Lasiurus intermedius)

b. Sagittal crest absent or poorly developed; greatest length of skull less than $16 \mathrm{~mm}$ - evening bat (Nycticeius humeralis)

\section{Acknowledgments}

Support for this project was provided by the USDA Forest Service, West Virginia University's Arlen G. and Louise Stone Swiger Fellowship, and the National Council of the Paper Industry for Air and Stream Improvement. Figures 1-8 were illustrated by B. Coslick; figure 9 was illustrated by G. Weis-Gresham. We thank the numerous students at the University of Georgia who tested earlier versions of the keys. Cover artwork by John MacGregor. This project would not have been possible without the professional support of B. R. Chapman and the late J. Laerm.

\section{Literature Cited}

Anthony, E. L. P. 1988. Age determination in bats. In: Kunz, T. H., ed. Ecological and behavioral methods for the study of bats. Washington, DC: Smithsonian Institute Press. 533 p.

Barbour, R. W.; Davis, W. H. 1969. Bats of America. Lexington, KY: University Press of Kentucky. 286 p.

Golley, F. B. 1962. Mammals of Georgia. Athens, GA: University of Georgia Press. 218 p.

Hoffmeister, D. F. 1989. Mammals of Illinois. Urbana, IL: University of Illinois Press. 348 p. 
Jenkins, J. H. 1949. A dichotomous key to the skulls of the recent land mammals of the southeastern United States. Athens, GA: University of Georgia. 87 p. M.S. thesis.

Laerm, J.; Menzel, M. A.; Krishon, D. M.; Boone, J. 1999. Morphological discrimination of the red bat (Lasiurus borealis) and the Seminole bat (Lasiurus seminolus). Journal of the Elisha Mitchell Scientific Society. 115: 131-139.

Lowery, G. H. 1974. The mammals of Louisiana and its adjacent waters. Kingsport, TN: Louisiana State University Press. 565 p.
Menzel, M. A.; Chapman, B. R.; Ford, W. M.; Menzel, J. M.; Laerm, J. 2000. A review of the distribution and roosting ecology of bats in Georgia. Georgia Journal of Science 58: 143-178.

Schmidly, D. J. 1991. The bats of Texas. College Station, TX: Texas A\&M University. 188 p.

Sealander, J. A.; Heidt, G. A. 1990. Arkansas mammals. Fayetteville, AR: University of Arkansas Press. 308 p.

Whitaker, J. O. Jr.; Hamilton, W. J., Jr. 1998. Manmals of the eastern United States. Ithaca, NY: Cornell University Press. 583 p. 




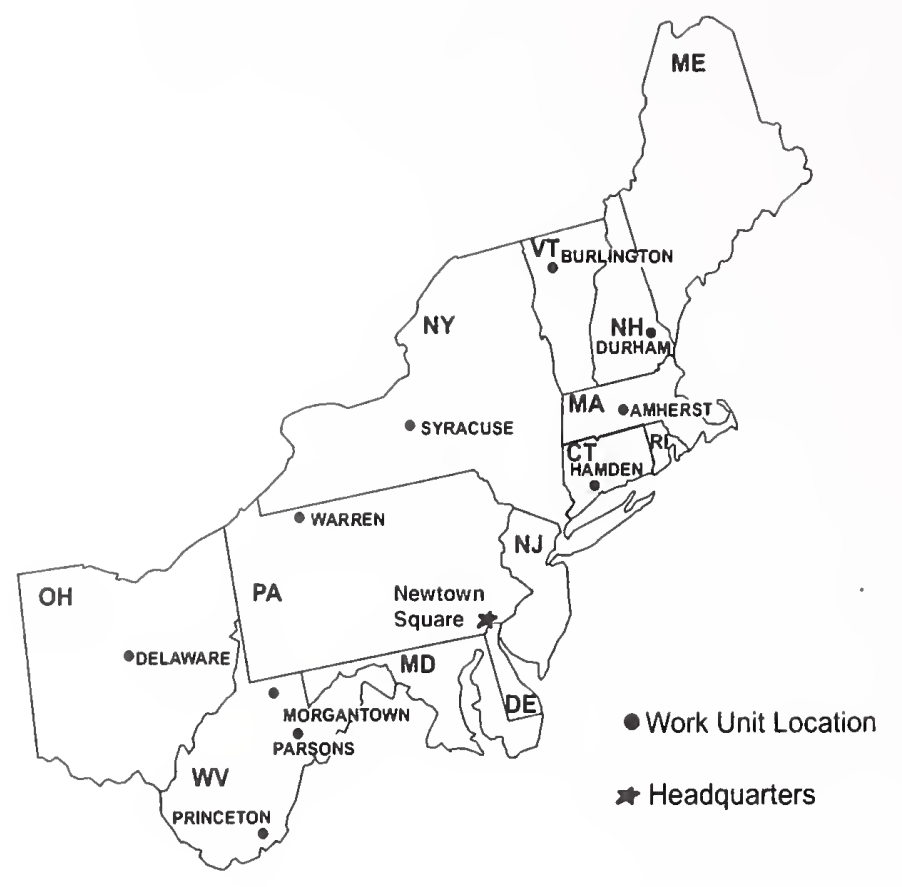

The U.S. Department of Agriculture (USDA) prohibits discrimination in all its programs and activities on the basis of race, color, national origin, sex, religion, age, disability, political beliefs, sexual orientation, or marital or family status. (Not all prohibited bases apply to all programs.) Persons with disabilities who require alternative means for communication of program information (Braille, large print, audiotape, etc.) should contact USDA's TARGET Center at (202)720-2600 (voice and TDD).

To file a complaint of discrimination, write USDA, Director, Office of Civil Rights, Room 326-W, Whitten Building, 1400 Independence Avenue, SW, Washington, DC 202509410 , or call (202)720-5964 (voice or TDD). USDA is an equal opportunity provider and employer.

Published by:

USDA FOREST SERVICE

11 CAMPUS BLVD SUITE 200

NEWTOWN SQUARE PA 19073

June 2002
For additional copies:

USDA Forest Service

Publications Distribution

359 Main Road

Delaware, $\mathrm{OH} 43015$

Fax: (740)368-0152

Visit our homepage at: http://www.fs.fed.us/ne 